\title{
Helping to promote psychiatry in less developed countries
}

\section{J. Broadhead, J. Piachaud \& J. Birley}

British psychiatry is appreciated all over the world for its empirical approach, its basis as a publicly funded service which is available to all citizens, and for its tradition (shared with the rest of British medicine) of educational connections with many other countries - members of the Royal College of Psychiatrists can be found in 70 countries worldwide. These connections are educational for all of those concerned. For visitors, the experience of seeing what can be done in a different context with different resources - both human and material - compels them, on their return home, to see their usual territory and practice in a new and revealing light.

There are many different ways in which psychiatrists can help their colleagues working in different, and often more deprived conditions in developing countries - from spending some considerable time in the country working in a direct clinical, teaching or administrative capacity, to giving the occasional lecture. Although the barrel of need is bottomless, it is the sense of doing something in the right direction that satisfies. To quote Edmund Burke, "he never made a greater mistake than he who did nothing because he thought he could only do a little".

This article provides some orientation to services in less developed countries. We focus on the developing Commonwealth and Eastern European countries. Whatever sort of visit the UK psychiatrist may make, and to whatever country, some general principles apply and these are outlined. Three examples are then included which demonstrate models of how mutually productive links can be made between UK institutions and developing world mental health services.

\section{Background}

\section{Developing countries}

In most developing countries, the majority of mental health care is provided by traditional healers. Until recently, as in the more industrialised regions, modern psychiatric care was generally provided through large, centralised asylums catering for people with mental illness who could not be managed in society. This system operated in parallel with, and in isolation from, traditional mental health practices. No attempt was made to extend services further than the hospitals because of cost, and myths that psychiatric disorders were rare and that traditional practices were always more appropriate than modern medicines for their treatment.

During the 1960s and 1970s, population surveys began to show that mental disorders were at least as common as in industrialised countries and that large numbers of people with mental illness, particularly those with common mental disorders, were attending primary care clinics. These findings led to calls for mental health services to be replanned. The World Health Organization (WHO) coordinated a series of multi-centred programmes which demonstrated that mental disorders could

Jeremy Broadhead is a consultant psychiatrist at the Bethlem and Maudsley NHS Trust. Before his senior registrar training in 1993, he worked for 2.5 years as a lecturer in psychiatry at the University of Zimbabwe Medical School. He is an advisor to the EC concerted action on mental health in Sub-Saharan Africa. Jack Piachaud is a consultant psychiatrist in learning disability at the Horizon and Parkside NHS Trusts and Honorary Senior Lecturer at the Imperial College School of Medicine at St Mary's Hospital. He has has worked for two years in Zimbabwe and remains involved in learning disability service developments. Jim Birley is Chairman of the Geneva Initiative on Psychiatry (Upper Bryn, Longtown, Hereford HR2 0NA). He has been Dean (1982) and President (1987) of the Royal College of Psychiatrists. Since retiring from the Maudsley Hospital in 1990, he has been Chairman of the Thorn Nurse Project's Steering Group, which has developed advanced training courses for Community Psychiatric Nurses in the UK. 
be managed at relatively low cost in primary care clinics, which provided a more accessible and acceptable alternative to hospital services.

Mental health issues and strategies for service development have now been included in many national policy documents. Legislation has been developed and non-governmental organisations have emerged to lobby on behalf of people with mental illness and their families. The treatment of psychiatric disorder, however, remains a low priority, and services in most low-income countries remain inadequate. Well-trained practitioners are still scarce, and drugs and psychosocial interventions are unavailable or of poor quality. In countries where expertise and resources do exist, they are likely to be concentrated away from the communities who most need them.

\section{Recognition of the burden of mental illness}

One of the many reasons for poor investment in psychiatric services has been the relative invisibility of psychiatric illness. In the established systems of public health accounting, the burden of illness resulting from psychiatric and behavioural disorders has been under-represented, because of the focus on mortality rather than morbidity or disability. However, the World Bank's (1993) World Development Report, which used disability-adjusted life-years (DALYs) as an index of the disability associated with diseases and injuries, demonstrated the degree of disability associated with psychiatric disorder worldwide. Mental illness was found to be one of the largest causes of lost years of quality life, accounting for $8.1 \%$ of all such years lost around the globe. Thirty-four percent of all disability was due to 'behaviour related conditions', for instance, violence, sexually transmitted diseases, diarrhoeal disease and road and other unintentional injuries. Box 1 tabulates the top ten causes of all DALYs lost at age 15-44 years in developing regions of the world.

The rapid development of urbanisation and migration to the cities has created increasing mental health problems. Demographic changes, with a relative increase in the proportion of young adults, will cause psychotic illness to become more common. Estimates of 16.7 million people with schizophrenia worldwide in 1985 appear set to increase to 24.5 million by the year 2000 .

\section{Eastern Europe}

The situation in Eastern Europe is rather different from those in other developing countries. Soon after
Box 1. Ten leading causes of DALYs at age 15-44 years in developing countries, 1990. (DALY disability-adjusted life-year) (data from Murray \& Lopez, 1996)

$\%$ total DALYs

1 unipolar major depression $\quad 9.9$

2 tuberculosis $\quad 5.4$

road traffic accidents $\quad 4.0$

war $\quad 3.5$

iron deficiency anaemia $\quad 3.4$

self-inflicted injury $\quad 3.4$

violence $\quad 3.2$

bipolar disorder $\quad 3.1$

schizophrenia $\quad 2.7$

10 alcohol use $\quad 2.6$

the Communists seized power, they decided to degrade the medical profession - a bourgeois organisation - both politically and intellectually. Doctors lost their professional independence and came under the control of the Party. Contacts with the West - both personal and through books and journals - were greatly reduced, and specialists were trained, often without any preceding general experience, in one year or less. There was little scope for individual initiative. The degree of degradation depended on the duration of exposure to totalitarian rule, the longest being in the core Soviet Union. Other 'iron curtain' countries also suffered depending on local political conditions - to the worst extent in Romania, the least in Poland.

The 'medical nomenklatura' controlled education and academic appointments and had little regard for the general standards of care. For psychiatry, the situation was aggravated by the nomenklatura's connections with the KGB and the political abuse of psychiatry, and by the totalitarian antipathy to individuality and personal freedom, making it difficult - and impossible in formal teaching - to regard a person's aspirations and problems as a proper area for study or therapy. The psychiatric approach was mechanistic and based on putative brain pathology. This was particularly damaging for children with learning difficulties who were diagnosed as 'oligophrenic' and written off as nonparticipants in the Workers' State. This system lasted for between 40 and 70 years. It ceased about 10 years ago, leaving a rigid apparatus without the skills, knowledge or attitudes necessary for coping with political and social change and the increasing poverty of the public services.

However, like plants in a desert, beneath the desolate surface very many people managed to 
maintain a private life which was generous, humane and original and they brought this spirit into their work. Among them were psychiatrists, who emerged in the 1990s with the purpose of reforming and improving their speciality. It is these people, now from many disciplines, who constitute the 'Reformers Group' of the Geneva Initiative on Psychiatry.

\section{Developing a strategy for mental health services}

The international mental health community has devised principles that should underlie strategies to develop psychiatric services (see Box 2). At the top of the list is the need to raise awareness of mental illness and the disability associated with it. As a result, mental health must be included in national, regional and international health agendas. The role of mental health services in tackling these problems can be evolved and publicised. Gradually, steps must be made to establish service descriptions, their objectives and budgetary allocations. To increase the recognition of psychiatric need, public health departments must document psychiatric morbidity and promote mental health targets.

A further objective in the development of any mental health service should be to make it accessible to the greatest numbers in need. This is something psychiatric hospitals, which were often placed many miles from any community at all, failed to do. An essential step will be the integration of mental health care into primary care services. World Health Organization demonstration projects have shown this can be achieved sustainably at relatively low cost. Where in-patient stays are required, these

\footnotetext{
Box 2. Strategies for developing mental health services

Raising awareness of disability due to psychiatric disorder

Establishing service descriptions

Making budgetary allocations

Recording of psychiatric disability data by public health departments

Integrating with primary care and with community workers and agencies

Defining legal safeguards for humane care Using specialist centres appropriately
}

should be in beds included in district hospitals, rather than in the psychiatric hospital, possibly many hundreds of kilometres away. As such, these more local psychiatric units can operate as extensions of the primary care services.

The successful inclusion of psychiatry into primary health care depends on enabling clinic staff to make basic diagnoses, to exclude physical illnesses and to know how to treat, for example, depression, schizophrenia and epilepsy. Inevitably, nurses or 'community workers' will become frontline practitioners and psychiatrists' roles will become those of educators and service developers. In the developing world, it is the families of people with psychiatrical illness who have to provide their care and who will need to be taught the necessary skills.

Finally, there is a need for a legal underpinning to the provision of humane mental health care. The United Nations commission on human rights concluded that in providing treatment and protecting those with mental illnesses and others from potential danger, basic human rights had also to be protected, and that legal safeguards were a prerequisite to humane care.

\section{General principles to apply to visits}

\section{Getting informed}

Visitors must see themselves as much as learners as teachers - this is essential. As much as possible should be learned about the particular host country before any visit is made - not only about the usual social, demographic and economic statistics and the organisation of the health services, but also about the local conditions, politics and hierarchical structure of the local society, both professional and general. Local beliefs about causation, manifes-

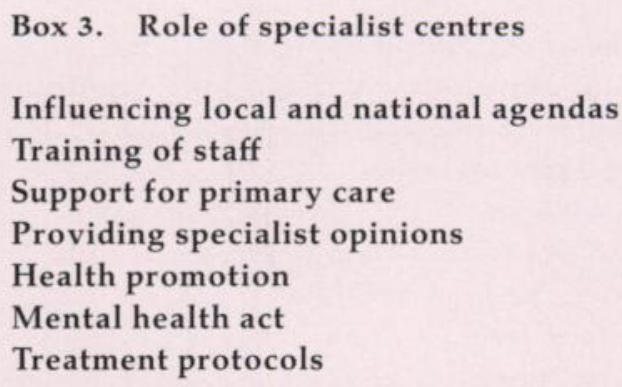


tations and treatment of the mentally ill also need to be explored. Some of this information, although often out of date, can be obtained before a visit, particularly from people who are already familiar with the place.

After arrival, the learning curve gets steeper, particularly concerning the existing social, psychological and medical channels and skills which that particular society employs to treat patients and their families. These may be quite unfamiliar to a Westerntrained psychiatrist, but they are always to be found and there will be much to be learned from them. Indeed, he or she should be careful to consider the consequences of the introduction of Western practice in case it damages the existing care system.

The host group will very quickly discover whether or not their Western visitor has taken the trouble to learn about their country. If so, and better still, if he or she has learnt to make a greeting and to speak even a few very simple phrases in their language, the visitor will be much more welcome.

\section{Defining goals}

Florence Nightingale famously said that a Sister should be judged by how well the ward functioned when she was not there. Every visitor should heed this message. Their aim should be to leave something which will continue after their departure. Their goal is to help educate, in its broadest sense, the future educators of that country.

The dictum that 'politics is the art of the possible' should be closely followed. Both parties may, in their initial enthusiasm, commit themselves to too much and overload themselves, professionally or personally. It is much better to start on a small project with clear and possible goals than to aim high and collapse, often with mutual recriminations, spoken and unspoken. Above all, it is important to do no harm.

Box 4. Principles applying to visits

Any visiting psychiatrist must be as fully briefed as possible prior to any visit

All joint projects must be carefully negotiated with all parties concerned and regularly reviewed

Links between institutions require: common interests, commitment at a senior management level, realistic objectives, mutual benefits and acceptable time commitments
No training scheme or research programme will succeed unless it is valued and owned by all those participating. This can only be done through negotiations and frank exchanges of view. As Western visitors tend to be treated with deference by their hosts, whatever their private reservations, the 'frank exchanges' often take some time to emerge. Any scheme will require a programme and a projected timetable by which progress, or lack of it, can be judged. Time should be set aside for regular review, involving all parties.

The host psychiatrists themselves must be included. They are the acknowledged leaders with some powers to effect change and to influence local bureaucrats and community leaders. They may also be, in some ways, the most vulnerable and thus resistant to change. Most senior psychiatrists, like other senior doctors in developing countries, occupy a high rank in a hierarchically structured group. They may also be sensitive about the deprivation of their resources and facilities compared with those of their Western visitors. It is important to ask them about their priorities and possible solutions. To suggest changes based on Western models, which often appear impossible, can be irritating and frustrating. If they do seem possible, they may be threatening to the hierarchy, for instance, by giving more skills and responsibilities to more junior personnel. It takes time for trust to develop, but it is worth it in order to develop a constructive partnership, which the local hosts (many of whom work in professionally isolated situations) will find encouraging.

In some situations, the act of contact may in itself be a sufficient goal, bringing a mutual exchange of ideas. In most situations, however, more tangible goals should emerge for the contact to be maintained. It is important to look for and acknowledge a mutual benefit of the contract - there are things to learn on both sides. Training often becomes an important element of such programmes.

\section{Focus of training}

Decisions regarding who should receive training depend upon the overall design of the project. In many cases this may be 'front-line workers', almost certainly neither psychiatrists nor nurses but people who have been selected to be a 'health worker' by their own community. While unfamiliar territory for most Westerners, this approach has been espoused for years by the WHO and many programmes devised. If a hospital is selected for 'improvement' and change, the nursing assistants may be the most appropriate target group. Most countries have no special training for psychiatric nurses. As most 
psychiatrists are not aware of the intricate details of the theory and practice of psychiatric nursing, they would be wise to include some nursing colleagues in the training scheme. The inclusion in a training scheme of patients and their relatives is always valuable. They feel that their needs are recognised and valued, and they have potential power, as citizens, to make political demands for better care, and also to link up with other relatives or patients groups, some of whom now have worldwide networks.

Collaboration in research projects is often of considerable value in creating partnerships, especially if that research can follow the principles of health systems research (see Box 5).

The educational aims of training anywhere can be subsumed under the familiar triad of attitudes, knowledge and skills. They are closely connected. For instance, if a lecturer is visiting a hierarchical institution where knowledge is handed down in a dogmatic way, he or she might consider reducing the length and content of his or her lecture, modelling a critical approach and allowing plenty of time for questions and comments, particularly from the more junior staff. He or she might also seek an opportunity to hold more informal seminars, discuss their current research, take part in case conferences and visit the clinical facilities. If he or she is visiting an academic unit which clearly serves only a small fraction of the local patients, the visitor might well request a visit to the local mental hospital and community services to meet the staff there and discuss their particular clinical and administrative problems. Thus, in addition to imparting some 'knowledge', he or she will have expressed an attitude that all staff looking after patients should be valued and given a chance to meet a foreign visitor. Often, it can be hard in these countries to gain copies of publications, rating scales and the like, but these can be brought easily by the visitor.

Box 5. Principles of health systems research

Research should be relevant and practical

Priorities for research should be determined by health staff and communities

Research should be carried out by those already working at ground level

The research is not complete until recommendations arising from the findings are implemented

\section{Examples of links established}

The following are example of links established between UK institutions and those providing or influencing service provision in less developed countries.

\section{Horizon NHS Trust and Zimcare, Zimbabwe}

On his return from working in Zimbabwe for two years, Dr Piachaud was able to interest a number of people within the Horizon NHS Trust in the issues of learning disability in Zimbabwe. Horizon specialises in learning disability so there was a natural focus. Of crucial importance was the support of the Chief Executive and the Chairman of the Trust. After several meetings and discussions sharing information about Zimbabwe, its culture, its economy and issues to do with learning disability, Horizon formally made contact with the Zimcare Trust in Zimbabwe, seeking their ideas as to how a mutually beneficial relationship could be developed.

The idea of mutual benefit was crucial to this exercise as an NHS trust could not embark upon a purely charitable exercise. The Zimcare Trust had to see the value in itself and its staff whether in terms of personal, professional or organisational development. The idea of mutual benefit also removes the notion of dependency, with both organisations operating on an equal footing with different experiences, skills and capacities.

The idea of exchange visits arose from the dialogue between the two organisations, and in 1994 three senior members of Zimcare and an officer from the Department of Social Welfare came over from Zimbabwe for a three-week visit to the UK. This enabled a more personal contact and the improved exchange of opinions, ideas and information. It gave the visitors a view of learning disability in the UK and, although at an extremely different resource base, many of the values, ideas and practices were common to both groups. The Horizon Trust specifically asked for feedback and this gave the visitors opportunity to critically examine a UK service from their perspective, which led to valuable insights into notions of dependency and overprotection.

The dialogue continued through correspondence and in October 1996, three therapists from Horizon visited Zimbabwe to run workshops for staff in their schools and centres for a two-week period - this had been identified by Zimcare as something they 
would like the Trust to offer. As part of the visit, the Chief Executive went over to see some of the services and discuss further contacts. A further set of visits has taken place to consider financial and organisational issues and to stimulate discussion at a strategic level within the organisation.

In addition to these visits, they have corresponded and exchanged materials on advocacy and teaching methods. Horizon have also raised funds within the Trust to help with the repair of a vehicle in Zimbabwe and with school fees.

\section{Parkside NHS Trust Westminster social services and learning disability services in Belgrade}

Dr Piachaud has conducted a similar exercise developing links between learning disability services in Westminster and in Belgrade, Federal Republic of Yugoslavia. This again had its origins in personal contact through visits made to Belgrade with the UK medical non-governmental organisation MEDACT. This cooperation involved Parkside NHS Trust, Westminster Social Services and the Westminster Society (which is a local branch of Mencap) and has now led to two exchange visits over the past two years.

Dr Piachaud notes that the emerging process starts with a personal interest following an overseas visit. This is taken to senior members of the UK organisation and their backing sought for cooperation with the overseas institution. On both occasions desribed, UK colleagues were interested and concerned to make the liaison successful. For the process to work, the link must be of mutual benefit and the time required must be manageable alongside normal service commitments.

\section{The Royal College of Psychiatrists and the Geneva Initiative on Psychiatry in the former Soviet Union}

The Geneva Initiative on Psychiatry has its origins in an organisation set up in the 1970s to campaign against the political abuse of psychiatry in the Soviet Union. Following the political changes of 1991, it changed its name and its function to concentrate on helping to revive psychiatry in the former Soviet Union - both professionally and ethically - while continuing to report any abuse, which still occasionally occurs. It is based in Holland, retaining its original Secretary, Robert van Voren, awarded an Honoraroy Fellowship of the College in 1997.
Its main activity is the workshop for 'reformers in psychiatry' from all over the former Soviet Union and other Eastern European countries, which is held three times a year, usually in Holland, but also elsewhere. In addition, it funds many projects in these countries. College members have participated in many ways. Dr Jim Birley is its current Chairman, and many others, including the College Secretary, have participated at the meetings and/or travelled to most of the countries concerned, from Albania to Ukraine. Other Western contributors have come from Argentina, Canada, Denmark, France, Holland and the USA.

The focus of its activities has been mainly on issues of human rights, professional independence and ethics, and the involvement of 'citizens' in psychiatry - patients, relatives, legislators and the media - and on the skills required for such activities, rather than on purely clinical skills and technical advances. A particularly successful project has been the training of psychiatric nurses, with teachers originally from the UK and Holland and a psychiatrist from Bulgaria (Professor Toma Tomov). There is now a joint training scheme, with its own teachers, between Bulgaria and Ukraine, which may be extended to other countries.

In addition, a printing press (second-hand from Holland) has been set up in Kiev which publishes books at very little or no cost, including many translations varying from reference texts, including ICD-10 and the Oxford Textbook of Psychiatry, to books for the general public, such as Living with a Mentally Handicapped Child.

\section{The Bethlem and Maudsley NHS Trust and Poiana Mare Hospital, Romania}

Dr Birley has been involved in a project to reform the Poiana Mare Hospital in Romania whose plight was publicised when the Lancet reported the findings of a visit in 1995 by the Council of Europe's Committee on Torture and Degrading Treatment (Rogers, 1998). The ward staff were untrained and demoralised and it was jointly decided to provide them with an educational programme aimed at the nursing assistants and nurses, which has been devised and taught by members of the Maudsley Hospital's nursing staff.

This project, funded by a private charity with assistance from The Bethlem and Maudsley Trust, will run for three years. So far, the results have been promising and it is intended to provide courses for the medical and administrative staff in the future. 


\section{Other ways to become involved in overseas projects}

International associations and meetings present the best opportunities to meet those involved in the promotion of mental health abroad and to learn of initiatives needing collaborators. The World Federation for Mental Health (WFMH; 1021 Prince Street, Alexandria, VA 22314-5968, USA; http:// www.wfmh.com) deserves special mention. It is a non-profit organisation, currently with a membership from 120 countries, founded in 1948 to advance, among all peoples and nations, the proper treatment and care of those with mental disorders and the promotion of mental health. Membership gives access to regional meetings and informative bulletins through which contacts can be readily established.

In response to the World Development Report in 1993 (World Bank, 1993) and the Harvard Report (Desjarlais et al, 1995), the WHO has created an Action programme entitled 'Nations for Mental Health'. The aim of this programme is to improve the mental health of the world's underserved populations. A substantial part of this initiative is being coordinated from the recently established WHO collaborating centre at the Institute of Psychiatry, London.

In addition to joining such organisations, we would encourage any psychiatrists with experience of collaborating with or working within services in the developing world to submit articles to the Psychiatric Bulletin describing what they are doing and whether they can place people on projects or know of a possible 'other partner'.

\section{Conclusion}

We have looked at some issues for doctors wishing to spend time overseas in developing countries. Such work is rewarding and stimulating. Increasingly, the Medical Royal Colleges appear willing to accredit such overseas experience if sufficient supervision can be built into the programme. In time, it may be possible for some overseas posts to become regularly available for some specialist registrars. For consultants, the undertaking of sabbaticals is easier and perhaps more appealing than in years gone by.

There are many doctors from the developing world here in the UK on the College-sponsored
Overseas Doctors Training Scheme. These doctors will be returning to their home countries to develop services and this presents a good opportunity for UK doctors - both trainees and consultants - to maintain links through correspondence and occasional visits to support training or review services.

We have also described how links can be made more formal through institutions by involving senior managers who may broaden the project from the purely clinical and take a longer-term perspective. The evaluation of such projects is important; objectives must be realistic and measurable and mutual benefits must be established.

We have given examples of links established with services in Africa and Eastern Europe. We know of other such projects, for instance in child psychiatry (a long-standing and successful partnership with St Petersburg) and another in its early stages with the Ukraine. Readers may well know of many others, and we would be pleased to hear about them - the frustrations as well as the achievements.

\section{References}

Desjarlais, R., Eisenberg, E., Good, B., et al (1995) World Mental Health - Problems and Priorities in Low. Income Countries. New York \& Oxford: Oxford University Press.

Murray, C. J. L. \& Lopez, A. D. (1996) The Global Burden of Disease: A Comprehensive Assessment of Mortality and Disability from Diseases, Injuries and Risk Factors in 1990 and Projected to 2020. Cambridge: Harvard University Press.

Rogers, A. (1998) Report reveals extent of abuse in Romania's mental hospitals. Lancet, 351, 656.

World Bank (1993) World Development Report 1993. Investing in Health. New York: Oxford University Press.

\section{Further reading}

Abas, M., Broadhead, J. Mbape P., et al (1994) Defeating depression in the developing world: a Zimbabwean Model. British Journal of Psychiatry, 164, 293-296

Appleby, L. \& Araya R. (1991) Mental Health Services in the Global Village. London: Gaskell.

Ben-Tovim, D. I. (1987) Developmental Psychiatry - Mental Health and Primary Health Care in Botswana. London \& New York: Tavistock.

Cohn, N. \& Piachaud, J. (1997) Psychosocial support in the shadow of war. Psychiatric Bulletin, 21, 714-715.

Guiness, E. A. (1992) Patterns of mental illness in the early stages of urbanisation. British Journal of Psychiatry, 160 (suppl. 16).

Kleinman, A. \& Cohen, A. (1997) Psychiatry's global challenge. Scientific American, 276, 74-77.

Leff, J. (1988) Psychiatry Around the Globe. A Transcultural View. London: Gaskell. 


\section{Multiple choice questions}

1. In developing countries, mental illness:

a causes little morbidity in rural areas

$\mathrm{b}$ includes the same major conditions as in the West

c does not respond to current drug therapies

$\mathrm{d}$ is best dealt with by establishing specialist hospital services in the major cities

e is primarily managed by traditional healers.

2. Psychiatrists in the UK who extend their professional interests overseas should:

a approach new situations without preparation as this may cause prejudice

b seek for mutual benefit rather than giving charity

c raise expectations in their overseas colleagues to drive projects forward and reach targets

d maintain a fixed attitude rather than change views to fit in with other customs

e seek the support of local colleagues and management.
3. When considering a mental health project with an overseas partner:

a this will only be useful if you are willing to spend at least three months overseas

b it is essential that an educational focus is built into it

c teaching the current UK Care Programme Approach must be one of the goals

$d$ this may benefit from more relaxed procedures around ethical approval

e it is best to focus on community-based staff rather than waste time with professional groups.

MCQ answers
$\begin{array}{llll}\text { 1 } & & & \\ \text { a F } & \text { a F } & \text { a F } \\ \text { b T } & \text { b T } & \text { b T } \\ \text { c F } & \text { c F } & \text { c F } \\ \text { d F } & \text { d F } & \text { d F } \\ \text { e T } & \text { e T } & \text { e F }\end{array}$

\section{New from Gaskell}

\section{Ethnicity: An Agenda for Mental Health}

\section{Edited by Dinesh Bhugra}

This book sets the scene for identifying and meeting the mental health needs of black and minority ethnic groups. Clinicians, researchers, academics, hospital managers, commissioners and voluntary organisation workers come together to discuss the problems in health care delivery and the way of moving the agenda forward. In addition to multi-disciplinary working the key emphasis here is in involving commissioners and voluntary organisations in deciding how best to meet the needs of the communities.

Features: $\quad$ Setting the agenda for meeting the needs of minority ethnic groups Multidisciplinary input

Multispeciality within psychiatry

Readership: $\quad$ Mental health professional, eg. psychiatrists, trainees, nurses, OT's, psychologists and social workers

April 1999, Paperback, ISBN $1901242153, £ 25.00$ 